CLINICAL STUDY

\title{
Cabergoline and the risk of valvular lesions in endocrine disease
}

\author{
Patrizio Lancellotti ${ }^{1}$, Elena Livadariu ${ }^{2}$, Muriel Markov ${ }^{1}$, Adrian F Daly ${ }^{2}$, Maria-Cristina Burlacu ${ }^{2}$, Daniela Betea ${ }^{2}$, \\ Luc Pierard ${ }^{1}$ and Albert Beckers ${ }^{2}$ \\ Departments of ${ }^{1}$ Cardiology and ${ }^{2}$ Endocrinology, Centre Hospitalier Universitaire de Liège, Domaine Universitaire du Sart-Tilman, University of Liège, \\ B-4000 Liège, Belgium
}

(Correspondence should be addressed to P Lancellotti; Email: plancellotti@chu.ulg.ac.be; A Beckers; Email: albert.beckers@chu.ulg.ac.be)

\begin{abstract}
Aims: The cardiac valvular risk associated with lower exposure to cabergoline in common endocrine conditions such as hyperprolactinemia is unknown.

Methods and results: We performed a cross-sectional, case-control echocardiographic study to assess the valvular status in 102 subjects receiving cabergoline for endocrine disorders and 51 matched control subjects. Cabergoline treatment ranged from 12 to 228 months, with a cumulative dose of 18-1718 mg. Valvular regurgitation was equally prevalent in both groups and was almost exclusively mild. Two cabergoline-treated subjects had moderate mitral regurgitation; there was no relationship between cabergoline dose and the presence or severity of mitral valve regurgitation $(P=\mathrm{NS})$. Mitral valve tenting area was significantly greater in the cabergoline group when compared with the control subjects $(P=0.03)$. Mitral valve leaflet thickening was observed in $5.9 \%$ of cabergoline-treated subjects; no relationship with the cumulative cabergoline dose was found. No patient had aortic or tricuspid valvular restriction. Conclusion: No significantly increased risk of clinically relevant cardiac valve disorders was found in subjects treated with long-term cabergoline therapy at the doses used in endocrine practice. While exposure to cabergoline appears to be safe during low-dose long-term therapy, an association with subclinical changes in mitral valve geometry cannot be completely excluded.
\end{abstract}

European Journal of Endocrinology 159 1-5

\section{Introduction}

Over the last decade, ergoline dopamine agonists have been increasingly used for treating patients with Parkinson's disease (1). These patients taking either cabergoline or pergolide are at increased risk of newly diagnosed degenerative heart valve disease, which is mostly mediated by the activation of the subtype 2 5-hydroxytryptamine receptor $\left(5-\mathrm{HT}_{2 \mathrm{~B}}\right)(2)$. The $5-\mathrm{HT}_{2 \mathrm{~B}}$ receptor is highly expressed in human heart valves. When stimulated, it promotes mitogenesis and proliferation of fibroblasts, resulting in an overgrowth valvulopathy $(3,4)$. In Parkinson's disease, the severity of cardiac valve regurgitation is directly related to the cumulative exposure to (duration and dose) cabergoline and pergolide (5-8).

Cabergoline is also a first-line agent for treating patients with prolactinomas, the major cause of hyperprolactinemia (9). Nevertheless, cardiac valve disease has not been reported as a risk in these patients who may require long-term, or even lifelong, treatment with dopamine agonist therapy. The absence of valvular lesion could be related to the absence of a systematic echocardiographic examination of cardiac valves in these patients, a case-control study lacking to date. As the doses of cabergoline used in hyperprolactinemia $(10,11)$ (weekly dose of $0.25-3.5 \mathrm{mg}$ ) are considerably lower than those used in Parkinson's disease (daily dose of 2-6 mg), it would be reasonable to assume a lower risk of valvular lesions (12). However, because dopamine agonist treatment usually starts at a young age and might be continued for up to three decades, the potential safety of low-dose cabergoline therapy might be counterbalanced. Whether young patients receiving low-dose cabergoline therapy for such a long period are at increased risk of valve disease is currently unknown. Moreover, the risk of valvular lesions might be greater in patients with resistant prolactinomas who require higher doses of cabergoline.

We hypothesized that long-term treatment with cabergoline for endocrine disease would be associated with an increased risk of cardiac valve lesions. To test this hypothesis, we undertook a cross-sectional, casecontrol echocardiographic study to identify the presence of cardiac valve disease and to quantify its severity in a cohort of patients receiving cabergoline for at least 1 year for the treatment of hyperprolactinemia.

\section{Methods}

\section{Patient population}

Between January and August 2007, all consecutive patients attending our outpatient endocrine clinic who 
were receiving treatment with cabergoline were screened for inclusion as subjects in this study. To be eligible, subjects had to have received treatment with cabergoline for at least 12 months. Exclusion criteria were: a previous history of cardiac valvular abnormalities, the previous use of anorectic drugs or drugs that caused hyperprolactinemia, and the presence of a pituitary adenoma that hypersecreted both prolactin and growth hormone $(\mathrm{GH})$ (as $\mathrm{GH}$ is independently associated with cardiac disease). Subjects that had hyperprolactinemia secondary to medication intake were not enrolled. Subjects with echocardiographic evidence of major cardiac and valvular abnormalities associated with a specific cause such as valvular calcifications, regurgitation associated with annular dilatation and left ventricular dysfunction or excessive leaflet motion were not included.

The study population consisted of 102 subjects who received cabergoline for the treatment of prolactinoma $(n=90)$, idiopathic hyperprolactinemia $(n=6)$, and nonsecreting pituitary adenomas $(n=6)$. Before receiving cabergoline, 30 subjects had received bromocriptine for a range of 2 months to 12 years $(<1$ year $=15$ subjects; 1 year to $<5$ years $=8$ subjects; and 5 to 12 years $=4$ subjects). Three patients received bromocriptine (duration: 10 years $(n=1)$ and 3 years $(n=2))$ followed by quinagolide (duration: 2 years $(n=1)$ and 3 years $(n=2))$. One subject received quinagolide alone for 3 months before cabergoline therapy. The cumulative dose of cabergoline was calculated for each patient as the sum of the doses used multiplied by the months of treatment (from the beginning of intake to the day of echocardiography).

A control group was recruited among healthy members of the hospital staff and from subjects attending the echocardiographic laboratory for evaluation of fitness or coronary risk factors. Exclusion criteria were the same as for the cabergoline-treated group and in particular, none had hyperprolactinemia or had ever received dopamine agonists or anorectic drugs. A pool of 82 subjects was identified and screened; from these, 51 control subjects were matched for age and sex in a 1:2 ratio with the cabergoline group. The two groups were also matched for the presence of major cardiovascular risk factors such as diabetes mellitus, hypertension, dyslipidemia, and history of coronary artery bypass grafting. The protocol was approved by the Institutional Review Board of the Centre Hospitalier Universitaire, Liège (Belgian Clinical Trial Number B70720072649; Belgian Online Registry of Human Studies www.clinicatrials.be) and all patients provided written informed consent.

\section{Echocardiographic measurements}

All patients and controls underwent a complete transthoracic echocardiographic examination using the same equipment (Vivid 7 GE, Vingmed Ultrasound,
Horten, Norway). All echocardiograms were performed by two experienced echocardiographers, with special attention towards valvular status and were interpreted by a third echocardiographer who was blinded to the study groups. Echocardiographic and Doppler data were obtained in digital format and stored on optical disks for off-line analysis. Valvular regurgitation was diagnosed using color-coded Doppler and by imaging multiple views. Quantification of regurgitant valve disease was made according to the guidelines of the American Society of Echocardiography (13). Valve regurgitation was graded as mild, moderate, or severe. Abnormal leaflet or cusp thickening was judged to be present when the thickness, local or widespread, exceeded $5 \mathrm{~mm}(6,8)$. Mitral and tricuspid valves were regarded as restrictive if leaflet stiffening and retraction towards the apex was identified. Mitral valvular tenting area - a marker of the apical displacement of mitral leaflets - was obtained from the parasternal long axis view at mid-systole and measured the area enclosed between the annular plane and the mitral leaflets $(14,15)$. The aortic valve was judged as being restrictive if the valve opened with evident doming of leaflets. Systolic pulmonary artery pressure was estimated from the systolic trans-tricuspid pressure gradient (in $\mathrm{mmHg}$ ) using the simplified Bernoulli equation $\left(\Delta P=4 V^{2}\right.$, where $V=$ maximal tricuspid regurgitant velocity in $\mathrm{m} / \mathrm{s}$ ).

\section{Statistical analysis}

Variables were expressed as medians, ranges, and mean \pm s.D. Differences between means were analyzed using Student's t-test. Categorical variables were compared with the $\chi^{2}$-test (STATISTICA version 6 , StatSoft, Inc., Tulsa, OK, USA). All $P$ values were calculated on the basis of two-sided tests, and a $P<0.05$ was considered significant. A linear regression analysis was used to assess the relationship between cumulative dose and mitral tenting area.

\section{Results}

\section{Study population}

The characteristics of patients and controls are listed in Table 1, which shows the matching of the group according to age, sex, and the prevalence of coronary risk factors. None of the cabergoline-treated patients had symptoms related to cardiac valve disease. The cabergoline dose ranged from 0.25 to $5.25 \mathrm{mg}$ per week. The cumulative dose ranged from 18 to $1718 \mathrm{mg}$ (median $204 \mathrm{mg}$ ) over a period of 12-228 months (median 79 months).

\section{Valvular regurgitation}

The prevalence of valvular regurgitation is reported in Table 2. Both in patients and control subjects, 
Table 1 Characteristics of controls and patients.

\begin{tabular}{|c|c|c|c|}
\hline Characteristics & $\begin{array}{l}\text { Controls } \\
(n=51)\end{array}$ & $\begin{array}{l}\text { Patients } \\
(n=102)\end{array}$ & $\begin{array}{c}P \\
\text { value }\end{array}$ \\
\hline Age - year* & $48 \pm 12$ & $51 \pm 14$ & NS \\
\hline Female sex - no. (\%) & $32(63)$ & $73(72)$ & NS \\
\hline Smoker - no. (\%) & $5(10)$ & $14(14)$ & NS \\
\hline Diabetes mellitus - no. (\%) & $8(16)$ & $11(11)$ & NS \\
\hline Hypertension - no. (\%) & $10(20)$ & $23(23)$ & NS \\
\hline Dyslipidemia - no. (\%) & $18(35)$ & 35 (34) & NS \\
\hline History of CABG - no. (\%) & $1(2)$ & $1(1)$ & NS \\
\hline $\begin{array}{l}\text { Maximal daily cabergoline } \\
\text { dose }-\mathrm{mg}^{\star}\end{array}$ & $N A$ & $1(0.25-4.5)$ & NA \\
\hline $\begin{array}{l}\text { Duration of cabergoline } \\
\text { therapy }- \text { months }^{*}\end{array}$ & NA & 79 (12-228) & NA \\
\hline $\begin{array}{l}\geq 60 \text { months of therapy - } \\
\text { no. }(\%)\end{array}$ & NA & $61(60)$ & NA \\
\hline $\begin{array}{l}\text { Cumulative cabergoline } \\
\text { dose }-\mathrm{mg}^{*}\end{array}$ & NA & $204(18-1718)$ & NA \\
\hline
\end{tabular}

CABG, coronary artery bypass grafting; *Median (range); NS, not statistically significant; NA, not applicable.

regurgitation of the aortic, mitral, tricuspid, and pulmonary valve was equally prevalent and almost exclusively mild in nature. Two cabergoline-treated patients had moderate mitral regurgitation. The mean cumulative dose of cabergoline in these subjects (184 $105 \mathrm{mg}$ ) did not differ from that in cabergoline-treated subjects with no $(276 \pm 315 \mathrm{mg})$ or mild $(366 \pm$ $382 \mathrm{mg}$ ) mitral regurgitation $(P=\mathrm{NS})$. No patient had received bromocriptine or quinagolide before cabergoline therapy. The mean systolic pulmonary artery pressure could be estimated in 50 patients and 12 controls and did not differ between the two groups $(20 \pm 8$ vs $20 \pm 7 \mathrm{mmHg}, P=\mathrm{NS})$. There was no difference in systolic pulmonary artery pressure according to the presence or severity of mitral regurgitation (none: $19 \pm 9 \mathrm{mmHg}$; mild: $21 \pm 6 \mathrm{mmHg}$; moderate: $22 \pm 6 \mathrm{mmHg} ; \mathrm{P}=\mathrm{NS})$.

\section{Valvular restriction}

None of the control group had evidence of leaflet restriction in any valve (Table 2). Among patients receiving cabergoline, six had localized $(n=4)$ or diffuse $(n=2)$ mitral valve leaflet thickening. However, the cumulative dose of cabergoline tended to be lower in these patients than in those without mitral valve restriction (no thickening: $331 \pm 359 \mathrm{mg}$; localized: $145 \pm 75 \mathrm{mg}$; diffuse: $171 \pm 98 \mathrm{mg}(P=\mathrm{NS}$ for all $)$ ). Five of these patients (three with localized and two with diffuse thickening) had mild mitral regurgitation and one had no regurgitation. The mean tenting area changed significantly with the extent of valvular thickening (no thickening: $1.32 \pm 0.30 \mathrm{~cm}^{2}$; localized: $1.57 \pm 0.55 \mathrm{~cm}^{2}$ ( $P=$ NS versus none); diffuse: $1.60 \pm$ $0.28 \mathrm{~cm}^{2}$ ( $P<0.05$ versus none). Overall, the systolic tenting area was greater in patients with diffuse/ localized mitral valve thickening than in controls $(P<0.05)$. Diffuse mitral valve leaflet thickening was observed in two patients who had previously received both bromocriptine and quinagolide before cabergoline therapy. The duration of bromocriptine treatment in these two patients was 3 and 10 years, while the duration of cabergoline treatment was 40 and 70 months.

The mitral tenting area was significantly higher in patients than in controls. The mean tenting area was not correlated with the duration of cabergoline treatment or the cumulative dose received. The mean mitral tenting area did, however, increase significantly with the increasing grade of mitral valve regurgitation from none $\left(1.28 \pm 0.25 \mathrm{~cm}^{2}\right)$ to mild $\left(1.36 \pm 0.34 \mathrm{~cm}^{2}\right.$; $P=$ NS versus no regurgitation) to moderate $(2.19 \pm$ $0.06 \mathrm{~cm}^{2} ; P<0.001$ versus no or mild regurgitation) in patients who received cabergoline. When compared with control subjects, the mitral tenting area was numerically higher in treated patients with no or mild mitral regurgitation $\left(1.23 \pm 0.22\right.$ vs $1.32 \pm 0.29 \mathrm{~cm}^{2}$; $P=N S)$, but was significantly higher in patients with moderate regurgitation ( $P=0.025$ versus controls). No patient had aortic or tricuspid valvular restriction.

\section{Discussion}

The risk of unsuspected moderate-to-severe cardiac valvular lesions was not increased among patients who received typical doses of cabergoline for the treatment of endocrine conditions for up to 18 years. No relationship was found between the cumulative dose of cabergoline and the occurrence of cardiac valve lesions. This is in contrast to the findings with cabergoline at higher

Table 2 Valvular lesions in controls and patients.

\begin{tabular}{llll}
\hline Characteristic & Controls $(n=51)$ & Patients $(n=102)$ & Palue \\
\hline Systolic arterial pressure $(\mathrm{mmHg})$ & $132.3 \pm 11.9$ & $128.4 \pm 14.3$ & $\mathrm{NS}$ \\
Valvular regurgitation $(n(\%))$ & $5(9.8 \%) / 0 / 0$ & $17(16.7 \%) / 0 / 0$ & $\mathrm{NS}$ \\
$\quad$ Aortic - mild/moderate/severe & $22(43.1 \%) / 0 / 0$ & $46(45.1 \%) / 2(2.0 \%) / 0$ & $\mathrm{NS}$ \\
Mitral - mild/moderate/severe & $21(41.2 \%) / 0 / 0$ & $51(50 \%) / 0 / 0$ & $\mathrm{NS}$ \\
Tricuspid - mild/moderate/severe & $19(37.3 \%) / 0 / 0$ & $36(35.3 \%) / 1(1.0 \%) / 0$ & $\mathrm{NS}(0.08)$ \\
Pulmonary - mild/moderate/severe & & $0 / 6(5.9 \%) / 0$ & 0.03 \\
Valvular restriction $(n(\%))$ & $1.23 \pm 0.22$ & $1.34 \pm 0.32$ & \\
$\quad$ Leaflet thickening of aortic/mitral/tricuspid valve & & & \\
Mitral valve tenting area $-\mathrm{cm}^{2}$ & & & \\
\hline
\end{tabular}


cumulative exposure $(>3 \mathrm{mg} /$ day for $>6$ months $)$ in patients with Parkinson's disease in whom moderateto-severe regurgitation was found in at least one valve in $34 \%$ of patients (8). Leaflet restriction and fibrotic changes of the subvalvular apparatus were the most common morphologic changes related to cabergoline exposure in those patients and the pathology led to valvular insufficiency. Such findings have already had important practical implications with the withdrawal of pergolide from the USA market (16). Cabergoline has not suffered the same fate as it is only indicated for the treatment of hyperprolactinemia in the USA, but there has been significant concern regarding the relative lack of specific safety data in this setting (17).

\section{Cardiac valve status and cabergoline treatment}

The present echocardiographic case-control study is, to the best of our knowledge, the first to examine the prevalence of valvular regurgitation in a consecutive cohort of patients treated chronically with cabergoline for pituitary adenomas (predominantly prolactinoma) or idiopathic hyperprolactinemia. We found that valvular regurgitation (aortic, mitral, tricuspid, and pulmonary) was equally prevalent in cabergolinetreated patients and in controls. In both groups, regurgitation was almost exclusively of a mild degree and of no clinical significance. Two cabergoline-treated subjects had moderate mitral regurgitation and no subject treated with cabergoline had severe regurgitation of any valve. In the two cabergoline-treated subjects with moderate mitral regurgitation, the cumulative dose of cabergoline was similar to that in patients with no or mild mitral regurgitation and neither had received bromocriptine nor quinagolide before cabergoline therapy. It is important to note, however, that these two patients were asymptomatic. Clinical and echocardiographic followup at 6 monthly intervals has been instituted in these patients, although the clinically effective cabergoline dose ( 1 and $1.5 \mathrm{mg}$ a week) has not been modified. Significant changes in mitral valvular geometry - leaflet restriction or stiffening - as assessed by the systolic tenting area were observed in the two patients with moderate mitral regurgitation but not in the other patients or controls. The tenting area was not related to previous treatment with bromocriptine or quinagolide. The significantly increased mitral valve tenting area in subjects receiving cabergoline, although not correlated with total exposure or associated with clinical valvular compromise, is an intriguing finding. Recent work studying the effects of ergot and derivative dopamine agonists in Parkinson's disease has shown a positive relationship between treatment with dopamine agonists and a significantly increased mitral valve tenting area $(6,8,18)$. This effect of increased, albeit subclinical, mitral valve stiffness occurred in the presence or absence of clinical correlates of valvular damage. However, the current study is the first to show such an effect at the much lower dopamine agonist doses used in the treatment of endocrine disorders. The explanation for this potential effect is unknown, but it may herald a low-level effect of dopamine agonists via $5-\mathrm{HT}_{2 \mathrm{~B}}$ receptors that warrants further study in animal models and the maintenance of some degree of caution regarding a potential off-target effect of this class.

Mitral valve leaflet thickening was detected in 5.9\% patients and in none of the controls; however, it was not correlated with the cumulative dose of cabergoline. The two patients with diffuse mitral valve leaflet thickening had been treated with both bromocriptine and quinagolide before cabergoline treatment. No patient had aortic or tricuspid valvular restriction. The mean systolic pulmonary artery pressure - an indirect marker of the presence of significant valvular regurgitation - was not statistically different in treated patients and in controls.

\section{Clinical implications}

Hyperprolactinemia is a highly prevalent condition, occurring in $0.4 \%$ of the general population $(19,20)$. Prolactinomas, which are the most common type of pituitary adenoma, are the most frequent cause of persistent hyperprolactinemia that requires dopamine agonist therapy. Although cabergoline is usually administered at a median dose of $1 \mathrm{mg}$ /week, treatment may be required for many years. Some patients with hyperprolactinemia may be successfully withdrawn from cabergoline therapy (21); however, for those with persistent disease other treatment options are considerably less attractive. Bromocriptine is less well tolerated and has an unfavorable dosing regimen when compared with cabergoline. A role for non-ergot/ ergoline dopamine agonists has been less thoroughly validated in the treatment of hyperprolactinemia, although data on quinagolide are available (22). The risk-benefit ratio for surgery or radiotherapy for the treatment of all but the largest and most resistant prolactinomas would appear to be relatively unfavorable. Therefore, our results on long-term cabergoline therapy regarding the low risk of significant valvular lesions appear reassuring.

\section{Conclusions}

Unlike in Parkinson's disease, we found no significantly increased risk of clinically relevant valvular regurgitation in association with long-term cabergoline therapy at the lower doses used in endocrine conditions. Cabergoline at a mean cumulative dose of $320 \mathrm{mg}$ was associated with a higher mitral valve tenting area than in controls, which may indicate low-level stiffening of the valves in the absence of more profound deformation. While this exposure to cabergoline appears to be safe during long-term therapy for hyperprolactinemia, an 
association between low-dose cabergoline and alterations in mitral valve geometry requires monitoring and further investigation to determine potential causality.

\section{Conflict of interest}

None of the authors report any conflicts of interest related to the study.

\section{References}

1 Nutt JG \& Wooten GF. Diagnosis and initial management of Parkinson's disease. New England Journal of Medicine 2005353 1021-1027.

2 Rothman RB, Baumann MH, Savage JE, Rauser L, McBride A, Hufeisen SJ \& Roth BL. Evidence for possible involvement of 5-HT(2B) receptors in the cardiac valvulopathy associated with fenfluramine and other serotoninergic medication. Circulation 2000102 2836-2841.

3 Jahnichen S, Horowski R \& Pertz HH. Agonism at 5-HT2 receptors is not a class effect of the ergolines. European Journal of Pharmacology $2005513225-228$.

4 Roth BL. Drugs and valvular heart disease. New England Journal of Medicine 2007356 6-9.

5 Schade R, Andersohn F, Suissa S, Haverkamp W \& Garbe E. Dopamine agonists and the risk of cardiac-valve regurgitation. New England Journal of Medicine 2007356 29-38.

6 Zanettini R, Antonini A, Gatto G, Gentile R, Tesei S \& Pezzoli G. Valvular heart disease and the use of dopamine agonists for Parkinson's disease. New England Journal of Medicine 2007356 39-46.

7 Pinero A, Marcos-Alberca P \& Fortes J. Cabergoline-related severe restrictive mitral regurgitation. New England Journal of Medicine 2005353 1976-1977.

8 Van Camp G, Flamez A, Cosyns B, Weytjens C, Muyldermans L, Van Zandijcke M, De Sutter J, Santens P, Decoodt P, Moerman C \& Schoors D. Treatment of Parkinson's disease with pergolide and relation to restrictive valvular heart disease. Lancet $2004 \mathbf{3 6 3}$ 1179-1183.

9 Casanueva F, Molitch ME, Schlechte J, Abs R, Bonert V, Bronstein MD, Brue T, Cappabianca P, Colao A, Fahlbusch R, Fideleff H, Hadani M, Kelly P, Kleinberg D, Laws E, Marek J, Scanlon M, Sobrinho LG, Wass JA \& Giustina A. Department of Medicine, Endocrine Division Guidelines of the pituitary society for the diagnosis and management of prolactinomas. Clinical Endocrinology 200665 265-273.

10 Schlechte JA. Clinical practice. Prolactinoma. New England Journal of Medicine 2003349 2035-2041.
11 Daly A, Rixhon M, Adam C, Dempegioti A, Tichomirowa MA \& Beckers A. High prevalence of pituitary adenomas: a cross sectional study in the province of Liège, Belgium. Journal of Clinical Endocrinology and Metabolism 200691 4769-4775.

12 Verhelst J, Abs R, Maiter D, van den Bruel A, Vandeweghe M, Velkeniers B, Mockel J, Lamberigts G, Petrossians P, Coremans P, Mahler C, Stevenaert A, Verlooy J, Raftopoulos C \& Beckers A. Department of Endocrinology. Cabergoline in the treatment of hyperprolactinemia: a study in 455 patients. Journal of Clinical Endocrinology and Metabolism 199984 2518-2522.

13 Zoghbi WA, Enriquez-Sarano M, Foster E, Grayburn PA, Kraft CD, Levine RA, Nihoyannopoulos P, Otto CM, Quinones MA, Rakowski H, Stewart WJ, Waggoner A \& Weissman NJ. American Society of Echocardiography. Recommendations for evaluation of the severity of native valvular regurgitation with two-dimensional and Doppler echocardiography. Journal of the American Society of Echocardiography $2003 \mathbf{1 6}$ 777-802.

14 Lancellotti P, Lebrun F \& Pierard LA. Determinants of exerciseinduced changes in mitral regurgitation in patients with coronary artery disease and left ventricular dysfunction. Journal of the American College of Cardiology 200342 1921-1928.

15 Pierard LA \& Lancellotti P. The role of ischemic mitral regurgitation in the pathogenesis of acute pulmonary edema. New England Journal of Medicine 2004351 1627-1634.

16 FDA Public Health Advisory: Pergolide. March 29th, 2007. http://www.fda.gov/cder/drug/advisory/pergolide.htm.

17 Sherlock M, Steeds R \& Toogood AA. Dopamine agonist therapy and cardiac valve dysfunction. Clinical Endocrinology $2007 \mathbf{6 7}$ 643-644.

18 Kim JY, Chung EJ, Park SW \& Lee WY. Valvular heart disease in Parkinson's disease treated with ergot derivative dopamine agonists. Movement Disorders 200621 1261-1264.

19 Mah PM \& Webster J. Hyperprolactinemia: etiology, diagnosis, and management. Seminars in Reproductive Medicine 200220 365-374.

20 Serri O, Chik CL, Ur E \& Ezzat S. Diagnosis and management of hyperprolactinemia. Canadian Medical Association Journal 2003 $169575-581$.

21 Colao A, Di Sarno A, Cappabianca P, Di Somma C, Pivonello R \& Lombardi G. Withdrawal of long-term cabergoline therapy for tumoral and nontumoral hyperprolactinemia. New England Journal of Medicine $20033492023-2033$.

22 Barlier A \& Jaquet P. Quinagolide - a valuable treatment option for hyperprolactinaemia. European Journal of Endocrinology $2006 \mathbf{1 5 4}$ 187-195.

Received 23 April 2008

Accepted 28 April 2008 